greater effort. They exert but little effect upon the dull and sluggish, while the full force of their pernicious influence falls upon those who need to be curbed instead of urged. Examinations undoubtedly cause more fret and worry and nervousness than any other school exercise. Examination week is everywhere, according to the observation of physicians and parents, a week of disturbed sleep, capricious appetite, night study and general ailing. They usually follow a long seasun of close application when mind and body are wearied, and the intense excitement induced by them often proves the "straw which breaks the back of mental and physical endurance." We would not abolish examinations, but would decrease their number and limit their power. The daily record for the entire term, rather than the results of that one nervous hour, should be the test of scholarship and promotion.

We have thus briefly reviewed some of the imperfections in our public school system which are sure to result in bad brain building. The school cannot afford to cripple its usefulness by antagonizing the well known laws of physical development, nor can the State afford to have it so crippled.

We repeat our conviction that the schools are but one factor, and perhaps the least, in undermining the physical vigor of American children. The only way, however to correct the evil practices and bad hygienic surroundings of street and home is through the school house.

The shortest route to the fireside is through the school house.

When teachers become thoroughly aroused to the importance of the physical development of the young, and familiar with the fundamental truths of physiology and sanitary science, then, and then only, will education become in fact what the root signification implies-a leading out-a symmetrical development of all the faculties, mental, moral and physical.

Our plea is for better school accommodations, including heating, lighting, ventilating and furnishing school buildings; for a later school age, lighter tasks, shorter hours and more play during the growing period of life; a period in which children are not only most readily but most permanently affected by every influence to which they are subjected.

We place no premium upon idleness or stupidity. Good digestion and healthy brains are not antagonistic : a torpid liver and brilliant cerebration are not necessary associates, but, on the contrary, the "mens sana in corpore sano" is as true to-day as when uttered by the heathen poet.

Ohio has upon her statute books a law which points the way to a removal of many of the objectionable features of our common schools: a law, be it said, to her credit, not found in any other State in the Union. The amended section 2135 of the Revised Statutes requires Boards of Health to inspect semi-annually and oftener, if necessary, the sanitary condition of all schools and school houses within the limits of the corporation. So far as we know the law sleeps upon the statute books. It certainly comes within the province of an association such as we organize to-day, to breathe into it new life.

\section{TOXIC EFFECT OF ALCOHOL IN EXSANGUINITY,}

BY JOSEPH SAGER, M.D., NORTH WASHINGTON, OHIO.

[Read to the Northwestern Ohio Medical Association, December II, 1883.7

On the third day of October, 1883 , I was called to attend Mrs. B., the case proving to be placenta prævia. She was an American by birth, aged $4 z$ years, and the mother of seven children. Upon arrival I found her almost totally exsanguinated and still bleeding. She wore the pallor of death, as much so as she did when she was dead. She could not speak above a whisper. The examination revealed a case of placenta prævia partialis; head presenting the mouth of the uterus very little dilated, with gushes of blood and no pain. The first I did I gave her a full dose of ergot, not for an oxytocic, but for a styptic; at the same time I gave her an injection of warm water followed with an injection of cold water. The opposite effect of cold water to warm water made an impression on the periphery, causing a reflex action, thereby closing up the uterine vessels. The effect was a happy one, the hæmorrhage became less and the pain came on.

The placenta occupied the right half of the lower segment, and being pushed through the os, I ruptured the membranes, allowed the escape of the liquor amnii, and forcibly dilated the mouth. The patient having been very much exsanguinated, I turned and delivered at once. The result of my labors was a male child, dead. By this time the patient being much exhausted, and from the loss of blood, she was thrown into convulsions. ${ }^{\prime}$ I administered chloroform at once, kept it up at intervals for six hours, by which means I controlled them; at the same time I put hot bricks to her feet and applied warm blankets to her body. At the expiration of six hours she was comfortably warm.

The hæmorrhage had ceased as soon as the child was born.

I would say, by way of parenthesis, that this patient was of a neurotic diathesis, so that when the convulsions were controlled, she was taken violently with intercostal neuralgia. I gave her a full dose of morphia hypodermically, which effectually controlled it.

The next day, Thursday, October 4, she felt quite comfortable. Friday morning, October 5, she felt very comfortable, took some light nourishment; inquired of the Presbyterian church, and how the new minister was liked.

Saturday morning, October 6 , I was called in haste to see Mrs. B., it was said she was dying. On arrival I found her in the following condition: She was crazed with neuralgic pains-facial, intercostal and sciatic neuralgia, with pain in her abdomen, some tympanitis, was very thirsty, called for water continually, very much prostrated, and difficult respiration.

On investigation, I learned that her drunkem brother had consulted a friend of his-a doctor-who

1There being no kidney complications. 
enjoined him to give his sister whiskey, whatever he did, if he wanted her life saved. Surreptitiously to myself he did it. He gave her whiskey Friday afternoon and Friday night, one pint, if not more, in tablespoonful doses. I stopped the whiskey, but it was too late. She died Sunday morning, October 7 , in the greatest agony-a sacrifice to despotism and egotistic ignorance.

Whatever may bethe effect of alcohol in health, the action on the nervous system, the effect it has on the circulation and nutrition, on the metamorphosis of tissues, and the arrest of the secretions, the toxic effect of alcohol is far greater in anæmia, and still more so in exsanguinity. When we take into consideration the poverty of the blood in exsanguinity, with but little reserve force, we can see at a glance that all the powers of nature must be supported by all conservative means which can be brought into play. The red corpuscles, which are so necessary to life must be cared for, and their genesis.

If we sacrifice a single red corpuscle, we hazard the life of our patient, as the force of the nervous system depends on the presence of oxygen in the red corpuscles.

It is an incontrovertible fact, that the toxic effect of alcohol in anæmia or exsanguinity is the destruction of the red corpuscles in the blood, either directly or indirectly.

It is conceded (and by good authority ${ }^{1}$ ) that alcohol favors the genesis of white corpuscles in health, which pabulum goes to form areolar tissue, muscle, etc., and every day's experience teaches us that the habitual moderate enjoyment of alcohol encourages a tendency to corpulency. Should this be the case in exsanguinity - the genesis of the white corpuscles favored, it would take the place of the red corpuscles, and prove calamitous to them.

The more probable theory is, that alcohol deoxidizes the red corpuscles. Hence their destruction.

Schulinus admits the destruction or decomposition of alcohol in the blood by way of deoxidizing the blood. He also says, by the introduction of half a drachm of alcohol into one of the lymphatic breasts of a living frog, the circulating fluid was changed from a bright red to a dark color.

Bonwetsch states that alcohol has an affinity for oxyhæmoglobin, destroying the oxygen in the red corpuscles; this he demonstrated by experimenting with ox blood.

I have myself injected alcohol into the cavity of the peritonæum of a live frog under the microscope. I could plainly notice in the circulating fluid in the web of the frog's foot, that at first the circulation was accelerated, but soon it became slower; the disks of the red corpuscles were flattened, while some were blasted or destroyed. The white corpuscles were unmolested, travelling slowly, adhering to the walls of the capillaries.

With these demonstrated declarations, let us look at the present case.

It is well known that in anæmia, we have to deal with the poverty of hæmoglobin in the red corpus-

\footnotetext{
1 Leibig.
}

cles, while in exsanguinity, we have to deal with the scantiness of the red corpuscles.

According to Flint and other physiologists, when the blood corpuscles are diminished in quantity by hæmorrhage, they are augmented $d c$ novo in the liquor sanguinis; this, then, is the reserve force.

Having taken care and fostered this reserve force by conservative means, our patient was in a fair way to recovery on Friday morning. The administration of whiskey not only bled our patient indirectly, but destroyed the red corpuscles of the blood and reserve force also.

The condition of the patient speaks for itself. The intense heat and thirst from the burning of oxygen, the condition of the nervous system, and hurried respiration, prove the destruction of the red corpuscles.

What else did it?

There was no other cause-I know whereof I speak.

Experience has proven it, and will prove it again, that alcohol, given to anæmic children, will produce asphyxia. Is it not reasonable, when the respiratory element itself is destroyed?

Alcoholic toxæmia will produce a constitutional tendency to inflammation. This we notice in debauchees. While in this debauched condition from alcohol, the least lesion tends to inflammation. The worst case of cellulitis I have had, was a case of this kind.

The white corpuscles are increased in the blood. At the same time the fibrin is increased largely also. These constitutional conditions will effect local changes in fresh lesions. The uterus in the puerperal state is in condition to become inflamed, if it has the least encouragement. It is a fresh lesion, although physiologically so. In addition there is hyperfibrination and degenerative changes going on.

Now let the blood become deoxidized, either by bad ventilation or a want of cleanliness, sepsis, or from any other source, there will be an inflammatory condition follow.

In my early practice I remember a physician who invariably "dosed" his puerperal patients with whisky. This physician had more puerperal fevers to contend with than any other physician in his vicinity. He finally sacrificed his own wife to this sinful practice.

I know of a bleeder, who whenever she would tak $\mathrm{e}^{\mathrm{e}}$ wine, the hæmorrhage was increased. She finally refused to take it at all. I gave her credit for her good sense.

From the foregoing considerations, we must conclude that in alcoholic toxæmia the red corpuscles in the blood are decreased by destruction, and the white corpuscles are relatively increased, either by genesis or as the red corpuscles are relatively decreased.

In conclusion I would say, the above considerations being true, we, as a profession, should speak against this sinful practice in thunder tones, that it may be felt through the country from center to circumference.

Dr. N. S. Davis, of Chicago, in his report on the 
practice of medicine to the Medical Society of the State of Illinois, discourages the use of alcohol as a remedy in the treatment of disease, in typhoid fever, and especially so where there is a cardiac weakness.

This paper was hastily written, not having time to gather and collect statistics on the subject. I submit it to the society for what it is worth, with the earnest desire to see the theory and practice of the use of alcohol as a remedy in exsanguinated subjects perish and be for ever wiped out.

Artificial Cultivation of Vaccine Virus.Dr. C. Quist, a physician of Helsingfors, Russia, announces in the St. Petersburger Meducinische Wochenschrift, that he has discovered a method by which vaccine virus can be cultivated in the laboratory. His claim, if true, would render vaccine farms superfluous, since all our virus should be grown in a watch-glass. It will, therefore, be examined with much interest.

Dr. Quist, by cultivating the micrococci of the vaccine lymph found that they developed into bacilli, which in turn produced micrococci again. After many experiments he found that the two things necessary for growth were oxygen and a proper culture fluid. 'The vaccine bacterium is, he says, "an exquisite ærobium." The best culture-fluid he found to be egg or serum albumen, to which is added glycerine (to prevent desication) and a little carbonate of lime. The following is one of the several formulæ which were used:

\section{$\mathbf{R}$}

Blood serum, I part.

Glycerine, I part.

Aquæ distill, 1 part.

Calcii carbonat, I-9ooth part.

'This fluid is sterilized by keeping it at a temperature of $60^{\circ} \mathrm{C}$. It is then spread upon a glass plate, a drop of vaccine lymph is mixed with it, and the whole is covered with a glass bell. The preparation is thus kept for a number of days. In six to ten days the surface is covered with the vaccine organisms. A little of this can be removed and inoculated with the result, according to Dr. Quist, of producing a perfect vaccine pustule. Our experimenter has found also that one inoculation of this cultivated virus produces immunity against a second. He does not, however, yet give evidence to show that these inoculations prevent small-pox.

It appears from reading the account of Quist's experiments that they were carefully conducted. The obvious criticism, however, is that they may only show that vaccine lymph can be largely diluted and yet retain its potency. - New York Medical Record.

Prof. Billroth's Antiseptic Precautions.-The Vienna correspondent of the Gazetta degli Ospitali was recently invited to a laparatomy in Prof. Billroth's clinique in the following note: "Dr. _- is hereby invited to the operation of - , which is to take place - It is understood that Dr. - undertakes not to visit the same day, before the operation, sick rooms, dissection rooms, or other places in the Pathological Institute, and not to wear clothes which he may be in the habit of wearing in visiting these places." -Lancet.

\section{MEDICAL PROGRESS.}

\section{ANATOMY AND PHYSIOLOGY.}

Complete Absence of Jejunum, Ileum, and the Greater Part of the Colon.-Mr. William Thomas reports a case in the Lancet, where in a premature birth at seven months of a female child, no anus was visible; no urethral orifice was visible, but a probe passed in the direction of the urethra for about two inches could be readily felt through the abdominal wall above the pubes. A second could be passed along the posterior wall of the vagina in the direction of the rectum for more than three inches. The child took the breast, but could not retain food for many minutes. It died in four days' time from exhaustion. The autopsy showed: no union between the pubic bones, an interval existing between them large enough to admit the finger. Stomach of normal size, connected with the duodenum by a constricted pylorus half an inch in length and rather less in diameter. The duodenum was an inch and a half in diameter in the distended state, and curved round the pancreas, to terminate on the left side of the spine by a blind extremity. There was no trace of any other part of the small intestine, nor of the cæcum, ascending or transverse colon. The intestine was recommenced by a blind portion of descending colon lying on the lower end of the left kidney, and continued by a sigmoid flexure and rectum, to terminate in the vagina.

A Case of Gasjric Fistula, with Physiological Observations.-DD. de Cirenville (Kevue Médicale de Suisse Romande), gives the case of a vine-dresser, 28 years of age, who suffered for some months from symptoms of gastric derangement which prevented his taking any nourishment. An examination showed an obstruction at the cardiac orifice of the stomach, with a distension of the cesophagus. It was found necessary to open the stomach on the left side, which was performed with success, a fistula established and relief afforded. The patient was fed through the fistula by means of a tube, and gained in weight in I I days from 105 to $I 32$ pounds. In the early treatmeut of the fistula a simple canula was used, which allowed some of the gastric juice to transude about and upon the open wound to the surface of the skin. 'This resulted, first, in an eczematous redness of the skin, followed by an ulceration due to a genuine digestion of the skin, but which, after the substitution of the canula used in physiological experiments for the simple canula, was readily healed. It was found impossible to overcome the resistance of the cardiac orifice, either by the sound introduced through the œsophagus or from below upwards through the stomach.

M. Herzen, Professor of Physiology, at Lausanne, adds to this record of the case, the results of some of his experiments in stomach digestion, which he intends to make more complete and to give more in detail. He notes the fact in this case that the stomach contains regularly, in the intervals of digestion, a considerable quantity of fluid, between 200 and 300 centimeters; that it contains no traces of the previ- 